\title{
Performance evaluation of filtration and ultrafiltration for municipal secondary effluent reuse
}

\author{
Jamalinezhad M. ${ }^{1}$, Hassani A.H. ${ }^{1 *}$, Borghei M. ${ }^{1}$, Amin M.M. ${ }^{2}$ \\ ${ }^{1}$ Department of Environmental Engineering, Faculty of Natural Science and Environment, Science and Research Branch, Islamic Azad \\ University, Poonak sq. Ashrafi Esfahani Blv., Hesarak, Tehran 14515-775, Iran \\ 2Department of Environmental Health Engineering, School of Health, and Environment Research Center, Research Institute for \\ Primordial Prevention of Non-communicable disease, Isfahan University of Medical Sciences, Hezar-Jarib Ave, Isfahan 81676-36954, Iran \\ Received: 01/02/2020, Accepted: 24/09/2020, Available online: 09/11/2020 \\ *to whom all correspondence should be addressed: e-mail: ahhassani@srbiau.ac.ir \\ https://doi.org/10.30955/gnj.003284
}

\section{Graphical abstract}

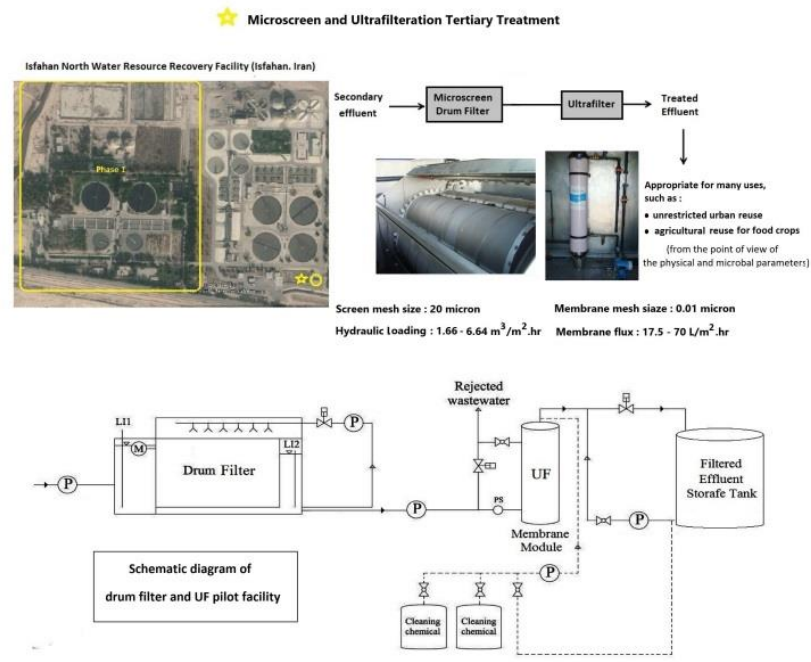

\begin{abstract}
This study aimed to evaluate the performance of microscreen drum filter and ultrafiltration (UF) as a tertiary treatment to improve the secondary effluent quality. Additionally, hydraulic loading of drum filter and membrane flux of UF were changed. On average, the use of drum filter and UF reduced TSS to $50 \%$ and $100 \%$, respectively. Furthermore, drum filter, on average, was capable of reducing turbidity and COD to 36 and $20 \%$, and UF decreased them to 76 and $39 \%$, respectively. Fecal coliform and total coliform were reduced to 74 and $76 \%$ in drum filter and 5.28 and $5.08 \mathrm{log}$ in UF, respectively. The results revealed that the combination of microscreen and UF is an effective hybrid process for reducing physical parameters and coliforms in secondary effluent so that it can meet the US Environmental Protection Agency standards for many uses, including unrestricted urban uses and agricultural irrigation for food crops.
\end{abstract}

Keywords: Disinfection, drum filter, microscreen, tertiary treatment, UF

\section{Introduction}

Municipal wastewater treatment and the use of effluent from the wastewater treatment plants (WWTP) for irrigation of green spaces, agricultural fields, groundwater recharge and so on is a practical solution for dealing with water scarcity. The conditions of operation of biological treatment processes create different qualitative conditions for the effluent of biological treatment units that does not sometimes meet the minimum quality standards, since treated wastewater contains a high percentage of suspended solids and pathogenic microorganisms, and therefore requires a tertiary treatment, such as the use of filtration and disinfection technologies.

Today, conventional disinfection alternatives including chlorine, chlorine dioxide, ozone, UV radiation and peracetic acid are used in wastewater treatment. Despite the advantages of these methods, several aspects restrict the use of these technologies on an industrial scale. UF membrane is an effective disinfection method to provide better effluent quality (Collivignarelli et al., 2018). The absence of regrowth and no formation of by-products are the main advantages of UF compared to other disinfection means (Gadani et al., 1996). In addition, from the point of view of the suspended solids and COD removal, UF process has higher efficiency in comparison with the other process combinations (Illueca-Muñoz et al., 2008). However, the biofilm formation on the membrane has a minor contribution to the membrane fouling mechanism, and the control of the transmembrane pressure parameter through the backwash period has a significant effect on the removal of matter accumulated on the membrane surface (Falsanisi et al., 2010), and also the use of chemicals can enhance backwash cleaning. (Xu et al., 2019). Chemical cleaning process applied to UF membranes has a considerable effect on microbiological quality and also prevents progressive fouling of the permeate zone (Arévalo et al., 2009). The coupling of coagulation with UF makes it possible to modify the configuration of the deposit on the membrane surface to greater-sized flocs (Abdessemed \& Nezzal, 2005). 
However, UF membrane requires suitable pretreatment such as macrofiltration in order to avoid fouling and module damage and optimize maintenance operations. The use of granular filter before the membrane in order to eliminate the problematic particles in the secondary effluent to UF would result in lower flow pressures and higher fluxes (Bourgeous et al., 2001).

Effluent quality of pretreatment units is variable and may affect the performance of disinfection systems applied subsequently (Gómez et al., 2006). One of the pretreatment methods is microscreen filtration system used for separation of particles in the tertiary wastewater treatment resulting from biological treatment (Ljunggren, 2006). Microsieve pretreatment by coagulation with anionic polymers prior to microfiltration (MF), results in a high flux and the best MF effluent water quality (Väänänen, 2017). Grau et al. (1994) used a microscreen with a mesh size of 10, 20 and $40 \mu \mathrm{m}$ and a hydraulic loading of 10-35 m $\mathrm{hr}^{-1}$ for advanced municipal wastewater treatment. Drum filter with mesh screen of $20 \mu \mathrm{m}$ was able to decrease SS to the extent of $75-85 \%$ (Grau et al., 1994). In the present study, for the purpose of tertiary municipal wastewater treatment, a UF disinfection technique was used following a microscreen pretreatment.

Tchobanoglous et al. (1998) used a pilot sand filter and UF for advanced wastewater treatment, in which the results showed that the function of UF membrane depends on the concentration of TS and the particle size distribution in the wastewater. Gómez et al. (2007) in consideration of UF with pretreatment by sand-pressure filter, showed that regarding sifting effect of particulate materials in membrane, UF obtained excellent water quality. In a study conducted by Abdessemed et al. (1999) using a combination of sand filters and UF, the increase in cross flow velocity in UF from $4 \mathrm{~m} \mathrm{~s}^{-1}$ to $6-7 \mathrm{~m} \mathrm{~s}^{-1}$ created a nearly linear relationship between permeate flux and transmembrane pressure (up to 1.3 bar). Also, Abdessemed et al. (2000), considered the treatment of secondary effluent by coagulation-adsorption coupling with UF as a tertiary treatment and they concluded that coagulation with ferric chloride and activated carbon adsorption has good performance in the reduction of the organic matter. Melgarejo et al. (2016) proved that tertiary treatment of WWTP effluent (Alicante, Spain) including coagulation, flocculation, sand filtration, and UF is suitable for urban uses (urban services), agricultural irrigation (all agricultural uses) and golf course irrigation (recreational use).

There are many publications on the use of membrane applications as tertiary treatment for the reuse of wastewater; however, few sources provide information about full-scale facilities that integrate the use of activated sludge with microfiltration or UF membranes. The purpose of this study was to improve the quality of secondary effluent in the operating conditions of Isfahan North (INWWTP), using a combination of microscreen and disinfection by UF membrane. In the present study, beside changing the hydraulic loading of drum filter and the membrane flux of UF, the efficiency of each unit in reducing physical, chemical and biological parameters was investigated.

\section{Materials and methods}

In this study, in order to investigate UF performance on the reduction of wastewater quality parameters, a pilot system was designed with UF and microscreen drum filter units and was installed at the outlet of the secondary sedimentation unit in INWWTP. Figure 1 shows the schematic diagram of the pilot plant and Table 1 shows the values of the effluent quality parameters of INWWTP.

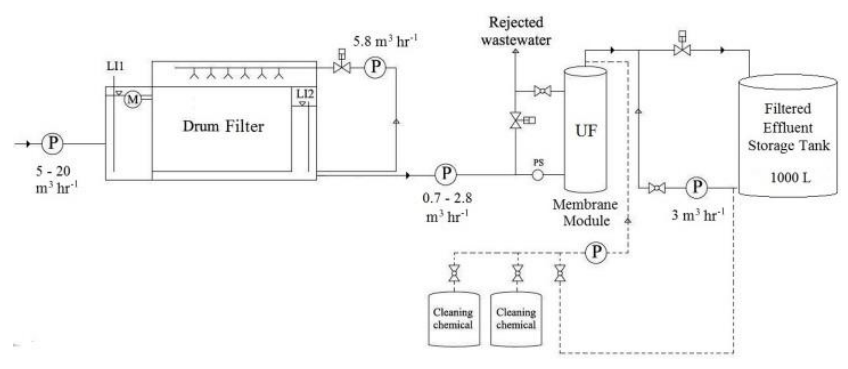

Figure 1. Schematic diagram of drum filter and UF pilot plant

\subsection{Pilot microscreen specifications}

For UF pretreatment, a filtration system of the type of microscreen drum filter with the main parts including feed pump, inlet flowmeter, drum filter framework, cartridges and screens, drum rotary gear motor, nozzles and backwash pump, outlet and inlet level meter and control system was used. The model of the machine was MTSM $1000 \times 1500 \mathrm{~mm}$ manufactured by the Passavant \& Watec Company and the body was made of stainless steel and screen material made from polyester fibre. The characteristics of drum filter are shown in Table 2.

\subsection{Pilot ultrafiltration specifications}

UF system was used with the main parts including the feed pump, inlet flowmeter, inlet pressure gauge, prefilter, UF membrane with its housing (membrane module), reclaimed effluent storage tank, chemical storage tanks for membrane chemical cleaning, membrane chemical cleaning pump and control system. The maximum inlet pressure to UF membrane was 3 bars. The model of the machine was LH3-1060-V manufactured by German Passavant \& Watec Company and the membrane type was internal pressure capillary and made of PVC. UF system specifications are shown in Table 3.

\subsection{Combined operation of pilot microscreen and ultrafiltration}

INWWTP includes two phases, which are operated by activated sludge process. The average treatment rating of INWWTP is $1.5 \mathrm{~m}^{3} \mathrm{~s}^{-1}$. The microscreen and UF system were continuously fed from the outlet of the first phase of INWWTP. The effluent with the flowrate between 5 to 20 $\mathrm{m}^{3} \mathrm{~h}^{-1}$ entered into drum filter and then the filtered effluent was pumped into UF with the flowrate of 0.7 to 2.8 $\mathrm{m}^{3} \mathrm{~h}^{-1}$.

In order to evaluate the performance of drum filter, the hydraulic loading rate with inlet flowrate was controlled at 
four levels of 1.66, 3.32, 4.98 and $6.64 \mathrm{~m}^{3} \mathrm{~m}^{-2} \mathrm{hr}^{-1}$ (first to fourth levels respectively). In order to create four levels of hydraulic loading, the inlet flowrates to drum filter were adjusted to 5, 10, 15 and $20 \mathrm{~m}^{3} \mathrm{hr}^{-1}$, respectively. As soon as clogging of the screens and increasing in the level difference between the inlet and outlet of the filter to the prescribed value in the control system $(8 \mathrm{~cm})$, the drum started rotating and then, using the nozzles, backwash process was done automatically.

In the next step, a portion of the filtered effluent was pumped into the membrane modulus of UF system. In order to evaluate the performance of UF, flux with inlet flow control was adjusted to four levels of 17.5, 35, 52.5 and $70 \mathrm{~L} \mathrm{~m}^{-2} \mathrm{hr}^{-1}$ (first to fourth levels respectively); inlet flowrate to UF was set to create four levels of flux at 0.7, 1.4, 2.1 and $2.8 \mathrm{~m}^{3} \mathrm{hr}^{-1}$, respectively. Due to the inlet pressure to the system and the manufacturer's recommendations, backwash frequency operation and backwash duration were chosen $20 \mathrm{~min}$ and $60 \mathrm{~s}$, respectively. The treated wastewater was then introduced into a $1000 \mathrm{~L}$ tank to be used for the membrane backwash.

The backwash operation was done in drum filter without stopping its operation; similarly, UF operation was done by cutting off the pumping into UF and stopping it from functioning. The backwash wastewater in drum filter was removed by the hopper and in UF system it was done by a solenoid valve.

Table 1. Secondary effluent characteristics of INWWTP

\begin{tabular}{ccccc}
\hline TSS $\left(\mathrm{mg} \mathrm{L}^{-1}\right)$ & Turbidity (NTU) & COD $\left(\mathrm{mg} \mathrm{L}^{-1}\right)$ & Fecal Coliform (MPN 100 $\mathrm{mL}^{-1}$ ) & Total Coliform (MPN 100mL ${ }^{-1}$ ) \\
\hline $8-66$ & $3.4-22.7$ & $35-70$ & $1.4 \times 10^{5}-1.6 \times 10^{7}$ & $3.5 \times 10^{5}-1.6 \times 10^{7}$ \\
\hline
\end{tabular}

Table 2. Characteristics of drum filter

\begin{tabular}{ccccccc}
\hline $\begin{array}{c}\text { Effective screen } \\
\text { area }\left(\mathrm{m}^{2}\right)\end{array}$ & $\begin{array}{c}\text { Screen } \\
\text { area } \\
\left(\mathrm{m}^{2}\right)\end{array}$ & $\begin{array}{c}\text { Screen mesh } \\
\text { size }(\mu \mathrm{m})\end{array}$ & $\begin{array}{c}\text { Drum } \\
\text { length }(\mathrm{m})\end{array}$ & $\begin{array}{c}\text { Drum } \\
\text { diameter }(\mathrm{m})\end{array}$ & $\begin{array}{c}\text { Backwash } \\
\text { flowrate }\left(\mathrm{m}^{\mathbf{3}} \mathrm{hr}^{-1}\right)\end{array}$ & $\begin{array}{c}\text { Feed pump } \\
\text { flowrate }\left(\mathrm{m}^{3} \mathrm{hr}^{-1}\right)\end{array}$ \\
\hline 3.01 & 5.15 & 20 & 1.5 & 1 & 5.8 & $5-20$ \\
\hline
\end{tabular}

Table 3. Characteristics of UF

\begin{tabular}{|c|c|c|c|c|c|}
\hline $\begin{array}{l}\text { Membrane } \\
\text { area }\left(m^{2}\right)\end{array}$ & $\begin{array}{c}\text { Pore size of } \\
\text { membrane }(\mu \mathrm{m})\end{array}$ & $\begin{array}{c}\text { Membrane } \\
\text { module } \\
\text { height }(\mathrm{mm})\end{array}$ & $\begin{array}{l}\text { Membrane module } \\
\text { diameter }(\mathrm{mm})\end{array}$ & $\begin{array}{c}\text { Feed pump } \\
\text { flowrate }\left(\mathrm{m}^{3} \mathrm{hr}\right. \\
\left.{ }^{1}\right)\end{array}$ & $\begin{array}{c}\text { Backwash } \\
\text { flowrate }\left(\mathrm{m}^{3} \mathrm{hr}\right. \\
\left.{ }_{1}\right)\end{array}$ \\
\hline 40 & 0.01 & 1715 & 277 & $1-3$ & 3 \\
\hline
\end{tabular}

Table 4. Levels of variables in sampling steps

\begin{tabular}{ccccccccccccccccc}
\hline Sampling steps & $\mathbf{1}$ & $\mathbf{2}$ & $\mathbf{3}$ & $\mathbf{4}$ & $\mathbf{5}$ & $\mathbf{6}$ & $\mathbf{7}$ & $\mathbf{8}$ & $\mathbf{9}$ & $\mathbf{1 0}$ & $\mathbf{1 1}$ & $\mathbf{1 2}$ & $\mathbf{1 3}$ & $\mathbf{1 4}$ & $\mathbf{1 5}$ & $\mathbf{1 6}$ \\
\hline Hydraulic loading levels for drum filter & & \multicolumn{1}{c}{} & & & & 2 & & & 3 & & & 4 & \\
\hline Flux levels for UF & 1 & 2 & 3 & 4 & 1 & 2 & 3 & 4 & 1 & 2 & 3 & 4 & 1 & 2 & 3 & 4 \\
\hline
\end{tabular}

\subsection{Sampling and analysis methodology}

In this research, sampling was performed in three locations including inlet into drum filter, outlet from drum filter (inlet into UF) and UF effluent. Considering four levels for hydraulic loading variable in drum filter and four levels for the flux variable in UF, 16 sampling steps and three times repetition in each step were carried out. Levels of variables in sampling steps are shown in Table 4.

According to three sampling points, 144 samples were collected. The samples were taken in each stage on a daily basis at intervals before and after UF backwashing. From all samples, microbiological parameters including fecal coliform and total coliform and physical parameters including TSS and turbidity and chemical parameters including $\mathrm{COD}$ and $\mathrm{pH}$ were measured according to the Standard Methods (APHA, 2012). Microbiological experiments were carried out using 15-tubes Most Probable Number method (MPN) and in different dilutions depending on the quality of each sample. The collected data were analyzed using statistical methods of analysis of variance (ANOVA) and paired t-test.

\section{Results and discussion}

The use of drum filter and UF in the reduction of microbiological and physicochemical parameters was statistically significant ( $p$-value $<0.05$ ). $\mathrm{pH}$ of the samples was measured which was between 6.7 and 8.8. Statistical analysis results using the ANOVA test showed that the hydraulic loading levels in drum filter and the levels of flux in UF did not have a significant effect on the removal efficiency of quality parameters. It was expected that increasing the hydraulic loading in drum filter would accelerate the clogging of the filter pores, and would increase the frequency and duration of backwash. Also, flux increase in UF would cause an increase in UF inlet flow pressure and the duration of reaching the maximum inlet flow pressure in the membrane modulus would be shortened; and in the long run, the system operating cycle gradually would be decrease and the duration of backwash would increase.

\subsection{Removal of TSS}

Using a drum filter, the overall mean TSS parameter was reduced by $50 \%$ (from $35.2 \mathrm{mg} \mathrm{L}^{-1}$ to $17.7 \mathrm{mg} \mathrm{L}^{-1}$ ). The mean values of the effluent TSS varied from 8.33 to $28.67 \mathrm{mg} \mathrm{L}^{-1}$. The average values of TSS in the inlet and outlet of drum 
filter are shown in Figure 2. Based on Figure 2, the effluent TSS values of drum filter depend on the values of the influent TSS. According to U.S. Environmental Protection Agency (U.S. EPA) Publications, using a drum filter as a tertiary treatment, the percentage of the removal of suspended solids depends on the influent solids concentration and it is $45-85 \%$ (U.S. EPA, 1975). The average removal percentage of TSS by sand filter macrofiltration, in the research conducted by Gómez et al. (2010), was 54.5\%. They also showed that the effluent TSS from the macrofiltration systems depended on influent TSS. Therefore, the performance of the microscreen as pretreatment was nearly comparable to the performance of the macrofiltration systems.

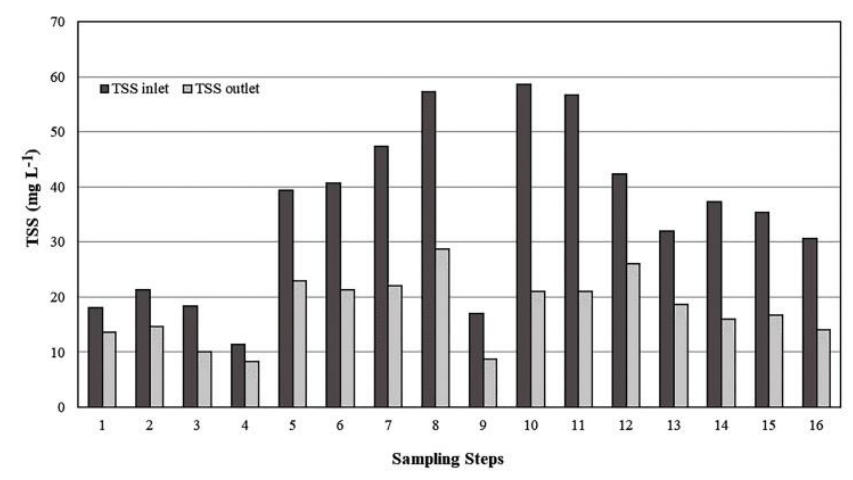

Figure 2. Inlet and outlet TSS of drum filter

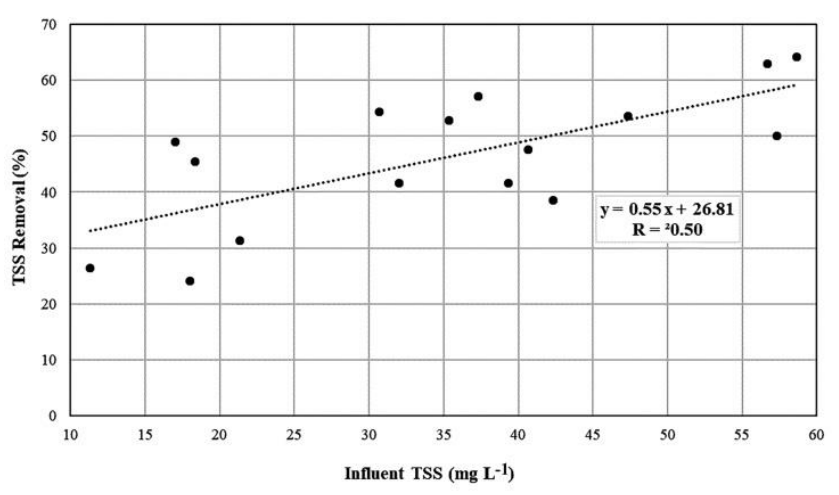

Figure 3. Removal efficiency of TSS in drum filter

In Figure 3, the percentage of TSS removal in drum filter has been presented based on average value of the influent TSS. According to figure 3 , by increasing the influent TSS to drum filter, the percentage of TSS removal increases linearly, so that the percentage of TSS removal decreased unexpectedly at the lowest level of hydraulic loading, which was due to the low influent TSS, compared to other levels.

In total, drum filter could decrease the concentration of this parameter, with any inlet concentration, to less than $35 \mathrm{mg} \mathrm{L}^{-1}$, whose amount would depend on the distribution of the existing particle size in the inlet into drum filter, i.e., the particles' diameter of less than $20 \mu \mathrm{m}$ in the secondary effluent was at most $35 \mathrm{mg} \mathrm{L}^{-1}$. Also, the increase of the influent TSS to drum filter or UF would cause a fast clogging of the filter pores and would increase the frequency and duration of backwash. Thus, in the present study, TSS concentration in the effluent of the drum filter provided the operational stability of the subsequent UF membrane process.

The values of TSS in the outlet of UF were independent from the TSS values in the inlet; therefore, all stages were below the detection limits. The complete removal of TSS occurred due to the pore size of UF membrane. Also, in similar studies, the complete removal of TSS in UF was obtained (Falsanisi et al., 2010; Gadani et al., 1996; JllluecaMuñoz et al., 2008).

\subsection{Removal of turbidity}

Drum filter reduced the turbidity parameter with an average removal of $36 \%$ (from 10.1 NTU to 6.5 NTU). The mean values of the effluent turbidity varied from 2.56 to 10.81 NTU, which drum filter reduced the turbidity caused by particles with a diameter larger than its pore size except when a peak occurred in the secondary effluent. The average values of turbidity in the inlet and outlet of drum filter have been presented in Figure 4. Based on Figure 4, the effluent turbidity values of drum filter to some extent depend on the values of the influent turbidity. The effluent turbidity of the macrofiltration systems (disc filter, pressure sand filter and mesh filter) in Gómez et al. (2010) research was shown to be dependent on the influent.

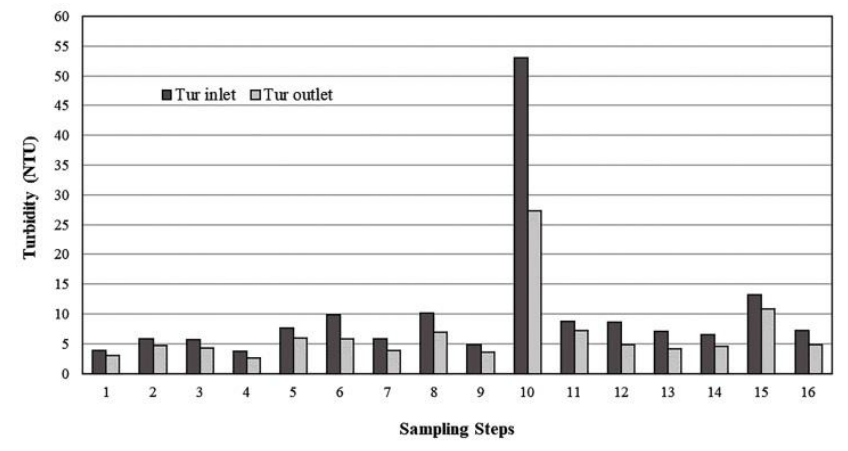

Figure 4. Inlet and outlet turbidity of drum filter

Using UF, the overall mean turbidity parameter was reduced by $76 \%$ (from $6.5 \mathrm{NTU}$ to $1.6 \mathrm{NTU}$ ). The mean values of the effluent turbidity varied from 1.08 to 2.28 NTU, in which UF reduced the turbidity caused by particles with a diameter between the pore size of drum filter $(20$ $\mu \mathrm{m})$ and UF membrane $(0.01 \mu \mathrm{m})$. The percentage of turbidity removal in UF as a function of the average values of the influent turbidity has been described in Figure 5. According to Figure 5, a rise in the amount of influent turbidity to UF results in an increase in the percentage of turbidity removal with logarithmic growth, so that at the second level of flux, because of the qualitative shock and the high rate of influent turbidity, the percentage of the turbidity removal was higher than other levels.

The results showed that the amount of turbidity in the outlet of UF was independent of the amount of turbidity in the influent. Accordingly, the increase in the influent turbidity to UF did not have significant effect on the amount of effluent turbidity, and therefore this parameter will not exceed 2.3 NTU; however, it is probable that in the long run, it simply would increase the inlet flow pressure to 
UF and requiring an increase in the frequency and duration of backwash. Arévalo et al. (2009) and Dialynas and Diamadopoulos (2008) also showed that the effluent turbidity was independent of the influent turbidity in UF.

Therefore, from the point of view of the physical parameters (TSS and turbidity), combination of microscreen and UF met the suggested regulatory guidelines of U.S. EPA for many effluent uses. (TSS $\leq 5$ $\mathrm{mg} \mathrm{L}^{-1}$ and Turbidity $\leq 2$ NTU).

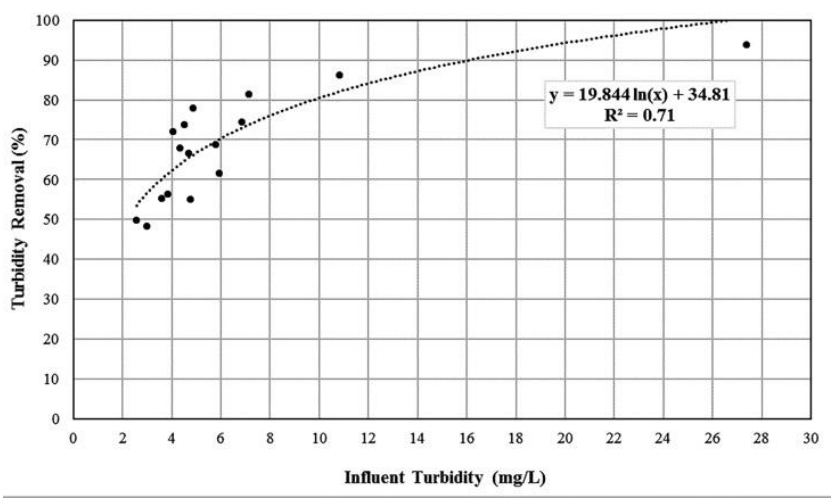

Figure 5. Removal efficiency of turbidity in UF

\subsection{Removal of $C O D$}

Drum filter reduced the COD parameter with an average removal of $20 \%$ (from $54.5 \mathrm{mg} \mathrm{L}^{-1}$ to $43.6 \mathrm{mg} \mathrm{L}^{-1}$ ). The mean values of the effluent COD varied from 29.5 to $51 \mathrm{mg} \mathrm{L}^{-1}$, except when a peak occurred in the secondary effluent, indicating the amount of organic matter associated with suspended particles larger than $20 \mu \mathrm{m}$ in the secondary effluent. The average COD values in the inlet and outlet of drum filter are presented in Figure 6. Based on Figure 6, the effluent COD values of drum filter depend on the influent COD values. Similar to turbidity removal, it is thus not possible to guarantee a specific COD in effluents from drum filter.

Using UF, the average COD parameter was reduced by $39 \%$ (from $43.6 \mathrm{mg} \mathrm{L}^{-1}$ to $26.5 \mathrm{mg} \mathrm{L}^{-1} \mathrm{v}$ ). The mean values of the effluent COD varied from 12 to $43.5 \mathrm{mg} \mathrm{L}^{-1}$. This removal of organic matter in UF indicates the fraction associated with suspended or colloids particles remained blocked on the membrane surface with a particle size between the pore size of drum filter $(20 \mu \mathrm{m})$ and UF membrane $(0.01 \mu \mathrm{m})$. In a study carried out by Illueca et al. (2008), COD decreased by $50 \%$ (from $58 \mathrm{mg} \mathrm{L}^{-1}$ to $29 \mathrm{mg} \mathrm{L}^{-1}$ ) using UF. In similar studies, Falsanisi et al. (2010), Melgarejo et al. (2016) and Nader and Bastaki (2004) reached COD removal efficiencies of $36 \%, 48.2 \%$ and $50 \%$ respectively.

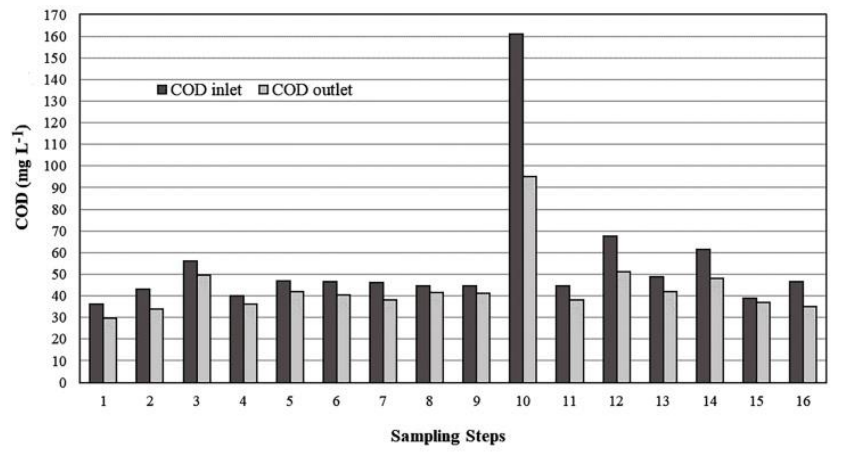

Figure 6. Inlet and outlet COD of drum filter

Thus, in this study, combination of microscreen and UF is suitable for reducing the COD to U.S. EPA standards safely in the discharged permits for agglomerations of more than 2000 population equivalent (COD $\leq 70 \mathrm{mg} \mathrm{L}^{-1}$ ) or cri-teria for industrial reuse in power plant (COD $\leq 60 \mathrm{mg} \mathrm{L}^{-1}$ ).

\subsection{Removal of coliform bacteria}

Drum filter reduced the fecal coliform parameter with an average removal of $74 \%$ (from $2.65 \times 10^{6} \mathrm{MPN} 100 \mathrm{~mL}^{-1}$ to $6.92 \times 10^{5} \mathrm{MPN} 100 \mathrm{~mL}^{-1}$ ). The mean values of fecal coliform removal varied from $18.75 \%$ to $91.19 \%$ (from 0.09 to 1.05 log reduction). Also, Drum filter reduced the amount of total coliform with an average removal of $76 \%$ (from $4.57 \times 10^{6} \mathrm{MPN} 100 \mathrm{~mL}^{-1}$ to $1.10 \times 10^{6} \mathrm{MPN} 100 \mathrm{~mL}^{-1}$ ), The mean values of total coliform removal varied from $5.71 \%$ to $90 \%$ (from 0.03 to 1 log reduction). This removal of coliform in drum filter indicates the amount of microbial contamination associated with suspended particles larger than its pore size in the secondary effluent.

In Figure 7, the percentage of total coliform removal in drum filter has been presented as a function of the average of influent total coliform. Based on Figure 7, with the increase of microbial load of the inlet into drum filter, the removal rate of the total coliform will increase logarithmically. Results showed that with any loading level and concentration of influent parameters, drum filter reduced fecal and total coliform to less than $1.6 \times 106 \mathrm{MPN}$ $100 \mathrm{~mL}^{-1}$.

Using UF, the overall mean fecal coliform parameter was reduced by $5.28 \log \left(99.99948 \%\right.$, from $6.92 \times 10^{5} \mathrm{MPN}$ $100 \mathrm{~mL}^{-1}$ to $\left.3.62 \mathrm{MPN} 100 \mathrm{~mL}^{-1}\right)$. The mean values of fecal coliform removal varied from 4.58 to $5.95 \mathrm{log}$ (from $99.99735 \%$ to $99.99989 \%)$. In Figure 8 , the log removal of fecal coliform in UF as a function of the average values of the influent fecal coliform has been described. According to Figure 8 , any increase in the amount of influent fecal coliform to UF causes an increase in the percentage of fecal coliform removal with logarithmic growth.

In similar studies done by Gómez et al. (2006) and Illueca et al. (2008), the removal efficiency of fecal coliform using UF was $99.998 \%$ and $100 \%$ respectively. 


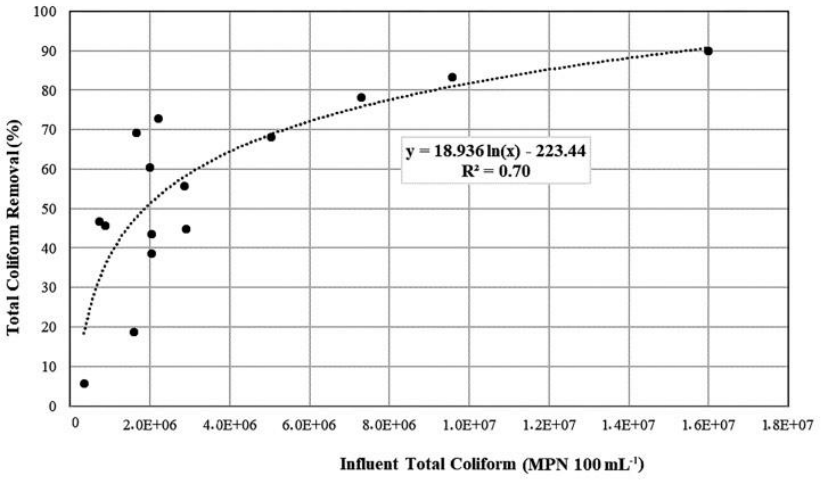

Figure 7. Removal efficiency of total coliform in drum filter

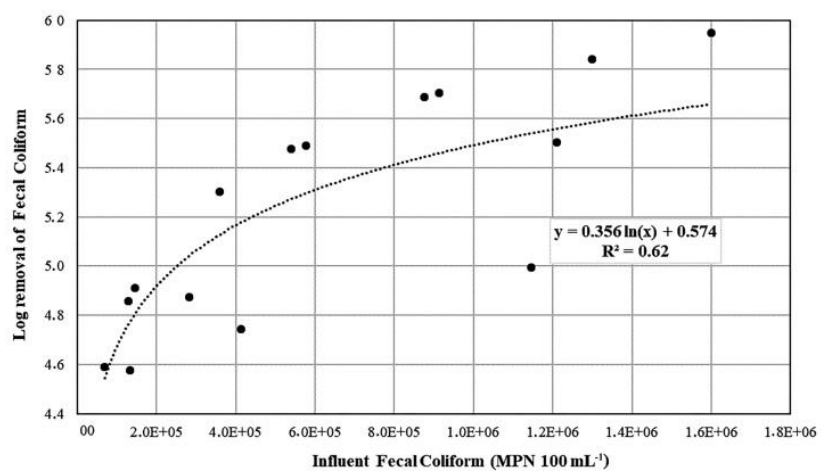

Figure 8. Log removal of fecal coliform in UF

Also, UF has on average reduced total coliform parameter by $5.08 \log \left(99.99916 \%\right.$, from $1.10 \times 10^{6} \mathrm{MPN} 100 \mathrm{~mL}^{-1}$ to 9.23 MPN $100 \mathrm{~mL}^{-1}$ ). The mean values of total coliform removal varied from 4.54 to $5.92 \log$ (from $99.99715 \%$ to 99.99988\%). Dialynas and Diamadopoulos (2008) also used UF for advanced treatment of the effluent, resulting in 99.96\% removal rate of total coliform.

In this study, the concentration of TSS, turbidity, COD and microbial parameters in the filtered secondary effluent did not affect the removal efficiency of the fecal and total coliform by UF system. Increasing the concentration of TSS and turbidity would only reduce the system operating cycle. Results showed that with any loading level and concentration of influent parameters, UF reduced fecal and total coliform to less than $14 \mathrm{MPN} 100 \mathrm{~mL}^{-1}$ and $49 \mathrm{MPN}$ $100 \mathrm{~mL}^{-1}$ respectively. Therefore, concentration of effluent contamination indicators did not depend on influent concentration.

This improvement in quality was due to the sifting effect of UF (Gómez et al., 2007). Stable microbiological quality in UF was, to some extent, similar to the results of some studies mentioned in the literature review (Arévalo et al., 2009; Falsanisi et al., 2010; Gadani et al., 1996; Gómez et al., 2006, 2007). Regarding the diameter of UF pores, the presence of insignificant coliform in UF effluent indicates the contamination of the permeate zone (membrane housing, membrane etc.) in UF and it is not due to the quality of the influent and the damage to the membrane (Arévalo et al., 2009; Gómez et al., 2006, 2007).

Thus, in a tertiary treatment by a combination of microscreen and UF, from the aspect of the microbial parameters, the effluent can be used in many cases, in accordance with the suggested regulatory guidelines of U.S EPA, such as unrestricted urban reuse, agricultural reuse for food crops and use in unrestricted Impoundments (fecal coliform $\leq 14 \mathrm{MPN} 100 \mathrm{~mL}^{-1}$ ).

\section{Conclusions}

The findings of this site-specific study showed that:

- Hydraulic load variable in the pretreatment performance by drum filter and the flux variable in the performance of UF disinfection had an insignificant effect on the removal efficiency of quality parameters; and with their increase, in a certain pore size, it can be expected that the systems operating cycle would decrease and the frequency and duration of backwash would increase.

- On average, the use of drum filter reduced TSS parameter by $50 \%$, which its removal percentage increased by increasing the influent TSS to drum filter. In total, drum filter can reduce TSS concentration to certain extent, indicating a maximum concentration of secondary effluent particles with less than the pore size of drum filter in diameter. Considering the pore size of UF membrane, the TSS values in the outlet of UF were independent of the TSS values in the inlet and they were below the detection limits.

- On average, using a drum filter reduced the turbidity parameter by $36 \%$ and the results showed that drum filter effluent turbidity depends on the influent turbidity. Also, UF reduced this parameter by $76 \%$ and the results showed that the effluent turbidity from UF is independent of the influent turbidity and in UF effluent, the concentration of colloidal particles with a diameter of less than the pore size of membrane would not exceed a certain amount.

- On average, using a drum filter decreased COD parameter by $20 \%$ and UF reduced COD by $39 \%$. The results showed that the effluent COD values of drum filter depend on the influent COD values. However, combination of microscreen and UF is suitable for safe reducing the COD for some uses.

- The use of drum filter reduced the fecal and total coliforms by $74 \%$ and $76 \%$, respectively. Also, the use of UF reduced the fecal and total coliforms by an average of 5.28 and $5.08 \mathrm{log}$, respectively and the insignificant presence of coliform in UF effluent indicates the contamination of the permeate zone. With the increase of microbial load of the inlet into drum filter and UF, the removal rate of the total coliform in drum filter and the fecal coliform in UF increase logarithmically.

- UF achieved a stable physical and microbiological quality, unaffected by characteristics of the secondary effluent and the membrane flux. In the 
present study, drum filter also provided stable operation of the subsequent UF membrane. Therefore, combination of microscreen and UF is an effective option to reduce the microbial and physical parameters of the secondary effluent sufficiently to meet U.S. EPA standards for many uses, including unrestricted urban reuse and agricultural reuse for food crops (fecal coliform $\leq$ $14 \mathrm{MPN} 100 \mathrm{~mL}^{-1}$ and Tur $\left.\leq 2 \mathrm{NTU}\right)$.

\section{Acknowledgements}

The authors gratefully acknowledge the financial support and assistance to this study by the Isfahan Water and Wastewater Co.

\section{Conflict of Interest}

The authors of this article declare that they have no conflict of interests.

\section{References}

Abdessemed D. and Nezzal G. (2005), Tertiary treatment of a secondary effluent by the coupling of coagulation-adsorptionultrafiltration for reuse, Desalination, 175(1), 135-141.

Abdessemed D., Nezzal G. and Ben Aim R. (1999), Treatment of wastewater by ultrafiltration, Desalination, 126(1), 1-5.

Abdessemed D., Nezzal G. and Ben Aim R. (2000), Coagulationadsorption-ultrafiltration for wastewater treatment and reuse, Desalination, 131(1-3), 307-314.

APHA (2012), Standard Methods for the Examination of Water and Wastewater, 22nd edn. American Public Health Association/American Water Works Association/Water Environment Federation, Washington, DC, USA.

Arévalo J., Garralón G., Plaza F., Moreno B., Pérez J. and Gómez M.A. (2009), Wastewater reuse after treatment by tertiary ultrafiltration and a membrane bioreactor (MBR): a comparative study, Desalination, 243(1-3), 32-41.

Bourgeous K.N., Darby J.L. and Tchobanoglous G. (2001), Ultrafiltration of wastewater: Effects of particles, mode of operation, and backwash effectiveness, Water Resource Manage, 35(1), 77-90.

Collivignarelli M.C., Abbà A., Benigna I., Sorlini S. and Torretta V. (2018), Overview of the Main Disinfection Processes for Wastewater and Drinking Water Treatment Plants, Sustainability, 10(1), 86, 1-21.

Dialynas E. and E. Diamadopoulos E. (2008), Integration of immersed membrane ultrafiltration with coagulation and activated carbon adsorption for advanced treatment of municipal wastewater, Desalination, 230(1-3), 113-127.

Falsanisi D. Liberti L. and Notarnicola M. (2010), Ultrafiltration (UF) Pilot Plant for Municipal Wastewater Reuse in Agriculture: Impact of the Operation Mode on Process Performance, Water, 2(4), 872-885.

Gadani V., Irwin R. and Mandra V. (1996), Ultrafiltration as a tertiary treatment: Joint research program on membranes, Desalination, 106(1-3), 47-53.

Gómez M., De la Rua A., Garralon G., Plaza F., Hontoria E. and Gomez M.A. (2006) Urban wastewater disinfection by filtration technologies, Desalination, 190(1-3), 16-28.

Gómez M., Plaza F., Garralón G., Pérez J. and Gómez M.A. (2007), A comparative study of tertiary wastewater treatment by
physico-chemical-UV process and macrofiltrationultrafiltration technologies, Desalination, 202(1-3), 369-376.

Gómez M., Plaza F., Garralón G., Pérez J. and Gómez M.A. (2010), Comparative analysis of macrofiltration processes used as pre-treatment for municipal wastewater reuse, Desalination, 255(1-3), 72-77.

Grau A., Haeusler M. and Schmitt W. (1994) Micro-straining as advanced treatment of wastewater applied to the main wastewater treatment plant in Wiesbaden, Water Science \& Technology, 29(12), 237-245.

Illueca-Muñoz J., Mendoza-Roca J.A., Iborra-Clar A., Bes-Pia A., Fajardo-Montañana V., Martinez-Francisco F.J. and BernacerBonora I. (2008), Study of different alternatives of tertiary treatments for wastewater reclamation to optimize the water quality for irrigation reuse, Desalination, 222(1-3), 222-229.

Ljunggren M. (2006) Micro screening in wastewater treatment an overview, Vatten, 62(2), 171-177.

Melgarejo J., Prats D., Molina A. and Trapote A. (2016), A case study of urban wastewater reclamation in Spain: comparison of water quality produced by using alternative processes and related costs, Water Reuse and Desalination, 6(1), 72-81.

Nader M. and Bastaki A. (2004), Performance of advanced methods for treatment of wastewater: UV/TiO2, RO and UF, Chemical Engineering and Processing, 43(7), 935-940.

Tchobanoglous G., Darby J., Bourgeous K. and McArdle J. (1998), Ultrafiltration as an advanced tertiary treatment process for municipal wastewater, Desalination, 119(1-3), 315-322.

U.S. EPA (1975), Process design manual for suspended solids removal, US Environmental Protection Agency, Technology Transfer, EPA 625/1-75-003a, Cincinnati, OH.

Väänänen J. (2017), Microsieving in municipal wastewater treatment: Chemically enhanced primary and tertiary treatment, Ph.D. Thesis, Department of Chemical Engineering, Lund University, Lund, Sweden.

Xu H., Koning J. and Geng Y. (2019), Reliability and efficiency of an advanced tertiary treatment process for wastewater reclamation, Journal of Water Reuse and Desalination, 9(4), 385-395. 